Marquette University

e-Publications@Marquette

$7-1-2003$

\title{
The Impact of Situational Constraints, Role Stressors, and Commitment on Employee Altruism
}

Steve M. Jex

University of Wisconsin - Oshkosh

Gary A. Adams

Marquette University, gary.adams@marquette.edu

Daniel G. Bachrach

Indiana University - Purdue University Indianapolis

Sarah Sorenson

University of Minnesota - Twin Cities

Accepted version. Journal of Occupational Health Psychology, Vol. 8, No. 3 (July 2003): 171-180. DOI. (C) 2019 American Psychological Association. Used with permission.

Gary Adams was affiliated with the University of Wisconsin - Oshkosh at the time of publication. 


\section{Marquette University}

\section{e-Publications@Marquette}

\section{Management Faculty Research and Publications/College of Business}

This paper is NOT THE PUBLISHED VERSION; but the author's final, peer-reviewed manuscript. The published version may be accessed by following the link in the citation below.

Journal of Occupational Health Psychology, Vol. 8, No. 3 (2003): 171-180. DOI. This article is (C) American Psychological Association and permission has been granted for this version to appear in ePublications@Marquette. American Psychological Association does not grant permission for this article to be further copied/distributed or hosted elsewhere without the express permission from American Psychological Association.

\section{The impact of situational constraints, role stressors, and commitment on employee altruism.}

Steve M. Jex

Bowling Green State U, Dept of Psychology, Bowling Green, OH, US,

Gary A. Adams

U Wisconsin--Oshkosh, Dept of Psychology, WI, US

Daniel G. Bachrach

U Alabama, Dept of Management, AL, US

Sarah Sorenson

U Minnesota, Dept of Human Resources \& Industrial Relations, MN, US

\section{Abstract}

This study investigated relations between 3 work-related stressors (role ambiguity, role conflict, and organizational constraints) and altruistic behavior in the workplace. It was predicted that each stressor would be negatively related to altruism and that these relations would be moderated by affective commitment (AC). Data from 144 incumbent-supervisor dyads revealed that all 3 stressors were weakly and negatively related to 
altruism. Two of these relationships were moderated by AC, although not as predicted. Organizational constraints were positively related to altruism among those reporting high levels of $A C$ but negatively related among those reporting low levels of AC. The pattern was exactly opposite for role conflict. Implications of these findings are discussed.

\section{Introduction}

The study of stress in organizations involves investigating the impact of stressful job conditions (termed stressors) on a variety of aspects of employee functioning (termed strains; Beehr \& Newman, 1978; Ivancevich \& Matteson, 1980; Jex \& Beehr, 1991). Although a great deal of research has explored the impact of job-related stressors on both psychological and physical well-being (e.g., Ganster \& Schaubroeck, 1991; Jackson \& Schuler, 1985), much less work has explored the impact of stressors on employee behavior, and job performance in particular. Furthermore, comprehensive reviews that have examined relations between stressors and job performance have generally shown that the magnitude of such relations is quite modest (e.g., Abramis, 1994; Jackson \& Schuler, 1985), although there is considerable variability among individual studies (Beehr, Jex, Stacy, \& Murray, 2000; Motowidlo, Packard, \& Manning, 1986).

According to Jex (1998), there are three possible explanations for the weak and inconsistent stressorperformance relations. First, stressors that are more proximal to performance should have a greater impact than those that are typically more distal. In other words, some stressors impede performance more directly than others. For example, not having the equipment one needs to perform one's job tasks is a more proximal stressor than having an argument with a coworker. Both of these stressors can obviously impede performance, but a lack of equipment is more likely to because it interferes more directly with performance.

A second reason is that most studies examining relations between stressors and job performance have relied on supervisory performance ratings ( $\underline{\text { Jex }, 1998)}$ ). Although supervisory ratings represent a viable means of measuring performance, there are biases in the rating processes (see Murphy \& Cleveland, 1990), and supervisory ratings are typically designed to measure a relatively narrow range of employee behaviors, most typically associated with in-role tasks. Performance, however, is a much broader construct that includes not only in-role behaviors but also organizational citizenship behaviors (Organ, 1994), refraining from counterproductive behavior (Murphy, 1994), and contributing innovative ideas to the organization (Damanpour, 1991). It is possible that stressors have different effects on these different dimensions of performance.

A third reason for weak and inconsistent stressor-performance relations is the presence of moderator variables. Many occupational stress studies have explored moderator hypotheses (see reviews by Jex \& Beehr, 1991; Kahn \& Byosiere, 1992) with varying degrees of success. Although occupational stress researchers have tended to favor stable individual difference moderators (e.g., self-esteem, sense of competence, Type A personality, and negative affectivity), it is possible that employees' feelings of commitment to the organization may also provide moderating effects, particularly with respect to relations between stressors and performance.

\section{The Present Study}

The present study was designed to assess relations between three stressors that have been examined extensively in the occupational stress literature (organizational constraints, role ambiguity, and role conflict) and one aspect of employee performance-altruistic behavior aimed at fellow employees. Employee altruism is defined as helpful and cooperative behavior that is aimed at other employees in the organization but that may ultimately benefit the organization. An example of this form of organizational behavior might be helping a fellow employee when he or she has fallen behind in his or her work (Podsakoff, Ahearne, \& McKenzie, 1997). Given this definition, altruism can be described as a form of organizational citizenship behavior (Organ, 1988), organizational spontaneity (George \& Brief, 1992), or contextual performance (Brief \& Motowidlo, 1986). 
The present study focused specifically on employee altruism for two primary reasons. First, even though all forms of extra-role behavior are discretionary, it is likely that employees have more discretion over altruism than many other forms of extra-role behavior. As an example, even though the dimension of organizational citizenship behavior labeled conscientiousness (Organ, 1988) is discretionary, an employee who fails to engage in conscientious behavior (e.g., being to work on time, attending meetings regularly) faces the real possibility of being reprimanded. On the other hand, the withholding of altruistic behavior (e.g., failing to help a fellow employee who is struggling on a work-related problem) is much less likely to be reprimanded.

A second reason is that altruism may have important health-related consequences for employees in organizations. Altruism can be viewed as a form of instrumental social support employees provide to each other on a day-to-day basis (Cohen \& Wills, 1985). As such, altruism not only has a positive impact on organizational performance (Podsakoff et al., 1997) but may also be an important form of social support that contributes directly to employee well-being (Beehr, 1995). If an employee experiencing high levels of stressors intentionally or unintentionally withholds altruistic behaviors from coworkers, those coworkers may reciprocate by withholding such behaviors in the future. This may set off a negative spiral that eventually leads to high levels of conflict and incivility, which may have a number of negative consequences for both individual employees and organizations (Andersson \& Pearson, 1999; Jex \& Spector, 2002).

There are many theoretical reasons why stressors may lead to a reduction in altruistic behavior. For example, research has consistently shown that stressors lead to negative emotional states such as job dissatisfaction, frustration, anxiety, and depression (Jex \& Beehr, 1991). Given that positive affect has been shown to be associated with helping behaviors both in and out of the workplace (Isen \& Levin, 1972; Organ \& Ryan, 1995), it plausible that employees experiencing high levels of stressors would be less likely to engage in altruistic behaviors. It has also been shown in laboratory studies that the presence of stressors leads to a narrowing of attentional focus ( Hockey, 1970) and decreased propensity to come to the aid of others (Matthews \& Canon, 1975; Sherrod \& Downs, 1974). Applying these findings to organizational settings, it is possible that employees experiencing high levels of stressors will tend to narrow their focus of attention to in-role tasks, and place less emphasis on extra-role behaviors such as altruism, as that is what they are typically held accountable for.

Given this general proposition that stressors lead to a reduction in altruistic behavior, an important issue to consider is whether all stressors are likely to have this impact. It is proposed in the present study that the stressors most likely to lead to a reduction in altruism are those that threaten to constrain performance or that force employees to make tradeoffs involving different aspects of performance. With this consideration in mind, the present study focused on role ambiguity, role conflict, and organizational constraints. Each of these is described below.

Role ambiguity, which as been studied extensively in the occupational stress literature (e.g., Jackson \& Schuler, $\underline{1985}$ ), occurs when employees are unclear about role requirements and performance standards (Beehr \& Bhagat, 1985). Given this uncertainty, an employee experiencing a high level of role ambiguity is faced with a dilemma that can only be resolved by seeking and obtaining additional role-related information. Furthermore, to obtain this information, employees typically must focus on in-role tasks and behaviors and thus will have less time for extra-role behaviors such as altruism.

Role conflict occurs when two or more requirements of an employee's role are conflicting; that is, complying with one role requirement makes it more difficult to comply with another (Rizzo, House, \& Lirtzman, 1970). As with role ambiguity, role conflict introduces uncertainty because the employee is uncertain whether he or she is successfully balancing all of his or her role requirements. To successfully cope with role conflict, an employee may try to meet all of the competing role demands, perhaps by working longer hours. Another option is to attempt to resolve some of the competing role demands, perhaps through negotiating with those who are 
communicating role-related information (e.g., "role senders"; Graen, 1976). In either case, the employee's focus is going to be much more on in-role than on extra-role tasks.

Organizational constraints represent conditions within organizations that make it more difficult for employees to do their jobs (Peters \& O'Connor, 1980). Common organizational constraints include interruptions from other people, lack of supplies and equipment, and budget cuts. Organizational constraints are obviously a source of frustration for employees but may be experienced as stressful for another reason. Specifically, employees are typically expected to perform their jobs well despite being faced with constraints. Thus, it is typically in an employee's best interest to try to perform well despite these constraints. To do this, employees will typically focus on in-role behaviors and pay less attention to more discretionary extra-role behaviors.

\section{The Role of Organizational Commitment}

Are all employees equally likely to withhold altruistic behavior in the presence of work-related stressors? It is proposed in the present study that a key factor in determining whether or not stressors lead to the withholding of altruistic behavior is an employee's level of attachment or commitment toward the employing organization. According to Meyer and Allen (1997), organizational commitment represents employees' feelings of loyalty and identification with their employing organization. They proposed that organizational commitment is multidimensional and distinguished between three forms that reflect the basis of an employee's commitment: continuance, normative, and affective. Continuance commitment reflects feeling of attachment toward the organization based on an employee's "sunk costs" that have accumulated over the years; normative commitment is based on an employee's feelings that remaining in the organization is the right or morally just thing to do; finally, affective commitment reflects genuine identification and psychological attachment to the organization.

Of the three forms of organizational commitment proposed by Meyer and Allen (1997), it was expected that the affective form would be most likely to moderate relations between stressors and altruism. This is because it would be very easy, and in fact may be seen as acceptable, for employees to withhold discretionary behaviors such as altruism when faced with job-related stressors. However, employees who have a genuine identification with and attachment to the organization may be reluctant to do this because they may see a reduction in altruism as being harmful to the organization. What this means, in essence, is that stressors should be unrelated to altruism among employees with high levels of affective commitment.

Conversely, for employees with low levels of affective organizational commitment, it was expected that stressors would be negatively related to altruism. Compared with those with high levels of affective commitment, employees with low levels are likely to view withholding of discretionary behaviors such as altruism as a more acceptable response to workplace stressors. This may be because they do not view withholding of discretionary behaviors as being harmful to the organization. It may also be that they see this as being harmful to the organization but simply do not care. Moreover, because extra-role behaviors such as altruism are monitored less closely than in-role behaviors, such a response to stressors is unlikely to lead to negative consequences for the employee.

Although neither continuance nor normative commitment was measured in the present study, it was expected that neither of these forms would moderate relationships between stressors and altruism. A high level of continuance commitment reflects an employee's belief that those costs associated with leaving the organization outweigh the benefits that could be had in another organization. There is no inherent reason to believe that one's level of continuance commitment would affect responses to stressors, unless perhaps if one's remaining in the organization depended on performing extra-role behaviors, which is typically not the case.

A high level of normative commitment, on the other hand, reflects an employee's belief that remaining in the organization is morally correct or "the right thing to do." Again, it is unlikely that an employee who feels highly 
obligated to remaining in an organization would necessarily go out of his or her way for the organization. That is, one may feel an obligation to the organization without feeling any sense of identification or attachment. Given this, there is no inherent reason that one's level of normative commitment would impact whether one engaged in extra-role behavior such as altruism in response to stressors.

\section{Summary of Hypotheses}

In summary, the following hypotheses were tested regarding the relationship between work-related stressors and employee altruism:

Hypothesis 1: A negative relationship between stressors and employee altruism is expected. Specifically, employees reporting high levels of organizational constraints, role conflict, and role ambiguity are expected to engage in less altruistic behavior than those reporting lower levels of these stressors.

Hypothesis 2. Affective commitment is expected to moderate the relation between stressors and employee altruism. Specifically, stressors will be unrelated to altruism among those reporting a high level of affective organizational commitment but will be negatively related among those with a low level.

\section{Method}

\section{Research Sample}

The research sample consisted of 144 employees and their immediate supervisors. Of these 144, 79 were employed at a medium-sized regional university in Wisconsin (Subsample 1), and 68 were employees of a large research university located in Indiana (Subsample 2). Employees of the university in Wisconsin performed a variety of nonfaculty jobs, whereas those from Indiana were employed in clerical positions in a variety of academic and nonacademic departments. Average age within the entire sample was 42.40 years $(S D=10.09)$, and the majority of respondents (80\%) were female.

\section{Measures}

\section{Stressors}

Stressors included role ambiguity, role conflict, and organizational constraints. Role ambiguity and role conflict were measured with the 14-item Rizzo et al. (1970) scale. Examples of role ambiguity items include whether respondents know what their responsibilities are (reverse coded) and know exactly what is expected of them (reverse coded). Examples of role conflict items include whether respondents receive incompatible requests from two or more people and know that they have divided their time properly (reverse coded). Reliability estimates for both scales were.79 and.82, respectively.

The presence of organizational constraints was measured with Spector and Jex's (1998) Organizational Constraints Scale (OCS). The OCS consists of 12 organizational conditions that may potentially constrain employees' performance. Examples of organizational conditions of the scale include poor equipment or supplies, the supervisor, and interruptions by other people. For each of these, respondents are asked to indicate the frequency with which it has a constraining effect on their performance. Coefficient alpha for this scale was.89.

\section{Altruism}

Altruism was measured with four items taken from Podsakoff et al.'s (1997) measure of organizational citizenship behavior (OCB). Altruism represents one of five recognized forms of OCB; however, because the present study was focused on the impact of stressors on altruism, only the altruism subscale from Podsakoff et al.'s measure was used. This measure was completed by each incumbent's immediate supervisor, which is common practice in research on extra-role behaviors (see Organ \& Ryan, 1995). Examples of items in this scale 
include encouraging each other when someone is down and helping each other when someone falls behind in his or her work. Coefficient alpha for this scale was.86.

\section{Affective organizational commitment}

Affective organizational commitment was measured with six items from Allen and Meyer's (1990) affective organizational commitment scale. Examples of items in this scale include whether respondents would be happy spending the rest of their career in the organization and whether the organization has a great personal meaning for the respondent. Coefficient alpha for this scale was.88.

\section{Procedure}

For Subsample 1, 525 employees were randomly selected from a master list of employees provided by the human resource department. These employees were mailed a questionnaire containing all self-reported items, along with a form requesting the name of their immediate supervisor and a consent form requesting permission to contact this person to obtain altruism ratings. Supervisors were contacted by campus mail and were asked to complete the altruism scale along with several demographic items. Of the 525 questionnaires mailed, 141 (27\%) employees returned completed questionnaires. Of these 141 employees, we were able to obtain supervisory reports of altruism from 80 (57\%). The total response rate was $15 \%$. Although this low response rate obviously raises concerns, there were no significant differences on any of the stressors or affective commitment ( $t s$ ranged from -1.58 to 0.98 , all nonsignificant) between those who provided complete data and those who provided only self-reports.

For Subsample 2, the human resource department provided a list of all individuals holding clerical positions at the university $(N=523)$. All of these individuals were contacted in person and $111(21 \%)$ agreed to participate in the study and provided self-report data. Of those providing self-report data, we were able to obtain supervisory ratings of altruism from 88 (79\%). Total response rate was $17 \%$. A comparison of those who provided complete data with those who provided only self-reported data revealed no significant differences on any of the stressors or affective commitment (ts ranged from 0.26 to 0.76 , all nonsignificant).

Descriptive statistics for the variables for each sample are provided in Table 1. Before combining the two samples, we calculated Box's $M$ to test the assumption that the relationships among the variables (the matrix of covariances) were the same across the two samples. The results of this test indicated that this assumption had indeed been met (Box's $M=20.05), F(15,80153)=1.29, p=.20$. In addition, because the items used to measure the predictors (role ambiguity, role conflict, organizational constraints, and affective commitment) were measured using a 7-point Likert-type rating scale in Subsample 1 and a 9-point Likert-type rating scale in Subsample 2, we transformed the scores on these variables to $z$ scores before combining the subsamples. The total sample size for both groups combined was 168, although deletion of missing data reduced this to 144 for the statistical analyses.

Table 1. Descriptive Statistics Across the Two Samples

\begin{tabular}{|l|l|l|l|l|}
\hline & Subsample 1 & & Subsample 2 & \\
\hline & (n=79) & & (n=68) & \\
\hline Variable & $\mathbf{M}$ & SD & $\boldsymbol{M}$ & SD \\
\hline Role ambiguity & 4.79 & 1.08 & 3.05 & 0.98 \\
\hline Role conflict & 2.97 & 1.09 & 3.36 & 1.18 \\
\hline Organizational constraints & 2.43 & 0.99 & 2.87 & 1.07 \\
\hline Altruism & 4.13 & 0.91 & 4.15 & 0.65 \\
\hline Affective commitment & 5.07 & 1.22 & 5.08 & 1.23 \\
\hline
\end{tabular}




\section{Results}

\section{Correlations}

As can be seen in Table 2 , organizational constraints was significantly related to altruism $(r=-.17, p<.05)$. Role conflict and role ambiguity were also both negatively related to altruism (-.15 and -.16, $p<.10$, respectively), although both correlations failed to reach a conventional level of statistical significance. Overall, then, the correlations provide partial support for Hypothesis 1 . Because there are theoretical reasons why gender might be related to altruism (Podsakoff, MacKenzie, Paine, \& Bachrach, 2000), the biserial correlation between gender and altruism was also calculated to help determine if gender could serve as a control variable in the regression analyses. This correlation was small and nonsignificant $(r=.12)$, and therefore gender was not used as a control variable in subsequent analyses.

Table 2. Intercorrelations Among All Study Variables

\begin{tabular}{|l|l|l|l|l|l|l|l|}
\hline Variable & $\mathbf{M}$ & $\mathbf{S D}$ & $\mathbf{1}$ & $\mathbf{2}$ & $\mathbf{3}$ & $\mathbf{4}$ & $\mathbf{5}$ \\
\hline 1. Role ambiguity & -0.01 & 0.71 & .79 & & & & \\
\hline 2. Role conflict & -0.04 & 0.66 & $.65^{* *}$ & .82 & & & \\
\hline 3. Organizational constraints & -0.04 & 0.65 & $.64^{* *}$ & $.75^{* *}$ & .89 & & \\
\hline 4. Altruism & 4.13 & 0.80 & $-.16^{\dagger}$ & $-.15^{\dagger}$ & $-.17^{*}$ & .86 & \\
\hline 5. Affective commitment & 0.03 & 0.78 & $-.44^{* *}$ & $-.36^{* *}$ & $-.38^{* *}$ & $.22^{* *}$ & .88 \\
\hline
\end{tabular}

Note. $\mathrm{N}=144$. Items on the diagonal are coefficient alphas; self-reported measures (role ambiguity, role conflict, organizational constraints, and affective commitment) were transformed to $z$ scores; supervisorreported altruism ranged from 1 to 5 .

$+p=.10$.

$* p=.05$.

$* * p=.01$.

\section{Moderated Regression Analyses}

To assess the moderating effects of affective commitment, we used a three-step hierarchical regression procedure (Cohen \& Cohen, 1983). As can be seen in Table 3, in Step 1 the stressors did not account for a significant portion of the variance in altruism when entered as a set. Affective commitment also failed to explain a significant portion of variance in Step 2, although the regression weight (derived from Step 3) was statistically significant $(p<.05)$. The set of interaction terms entered in Step 3 explained a significant portion of variance in altruism $\left(\Delta R^{2}=.07, p<.05\right)$. Of these three interaction terms, those representing the interaction between role conflict and affective commitment $\left(\Delta R^{2}=.03, p<.05\right)$ and between organizational constraints and affective commitment $\left(\Delta R^{2}=.04, p<.05\right)$ were both statistically significant.

Table 3. Summary of Moderated Multiple Regression Analysis Predicting Employee Altruism

\begin{tabular}{|c|c|c|c|c|c|c|c|c|c|}
\hline & $\begin{array}{l}\text { Step } \\
1\end{array}$ & & & $\begin{array}{l}\text { Step } \\
2\end{array}$ & & & $\begin{array}{l}\text { Step } \\
3\end{array}$ & & \\
\hline Step/predictor & B & $\Delta R^{2}$ & $\begin{array}{l}\text { Adj. } \\
R^{2}\end{array}$ & B & $\Delta \mathrm{R}^{2}$ & $\begin{array}{l}\text { Adj. } \\
R^{2}\end{array}$ & B & $\Delta \mathrm{R}^{2}$ & $\begin{array}{l}\text { Adj. } \\
R^{2}\end{array}$ \\
\hline \multicolumn{10}{|l|}{ Step 1} \\
\hline Role ambiguity & -.09 & .03 & .01 & -.04 & .02 & .03 & -.05 & .05 & $.07 * *$ \\
\hline Role conflict & -.02 & & & -.01 & & & .01 & & \\
\hline Organizational constraints & -.13 & & & -.10 & & & -.04 & & \\
\hline \multicolumn{10}{|l|}{ Step 2} \\
\hline Affective commitment & & & & $.17 \dagger$ & & & $.22^{*}$ & & \\
\hline
\end{tabular}




\begin{tabular}{|l|l|l|l|l|}
\hline Step 3 & & & \\
\hline Role Ambiguity x Affective Commitment & & & & .05 \\
\hline Role Conflict x Affective Commitment & & & & $-.49^{*}$ \\
\hline $\begin{array}{l}\text { Organizational Constraints x Affective } \\
\text { Commitment }\end{array}$ & & & & $.65^{* *}$ \\
\hline
\end{tabular}

Note. $\mathrm{N}=144$. Unstandardized regression weights (Bs) are reported.

$+p<.10$.

$* p<.05$.

$* * p<.01$.

To further explore these effects, we plotted separate regression lines for those high (1 SD above the mean) and low (1 SD below the mean) on affective commitment. In all three cases, the values for the stressors and crossproduct terms not involved in the interaction were set at their respective means. As can be seen in Figure 1 , the form of the interaction effects presented partially supports Hypothesis 2. Consistent with Hypothesis 2, the presence of organizational constraints was negatively related to altruism among those reporting low affective commitment.

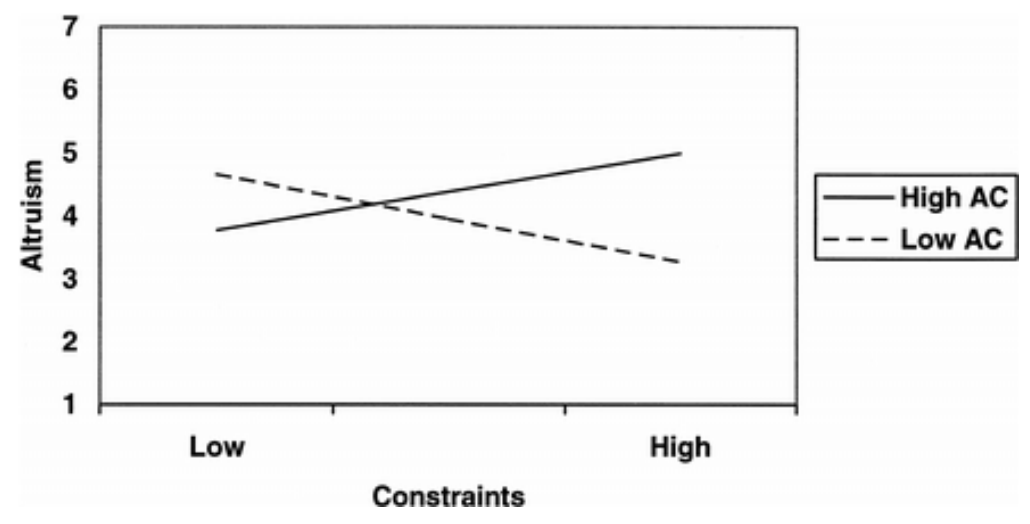

Figure 1. The relation between organizational constraints and altruism as a function of affective organizational commitment (AC)

However, contrary to predictions, the presence of organizational constraints was positively related to altruism among those reporting a high level of affective commitment. Recall that it was expected that stressors would be unrelated to altruism in this group.

As can be seen in Figure 2, the form of the interaction effects does not support Hypothesis 2. Specifically, role conflict was negatively related to altruism among those reporting high levels of affective commitment. For those reporting low commitment, role conflict was positively related to altruism.

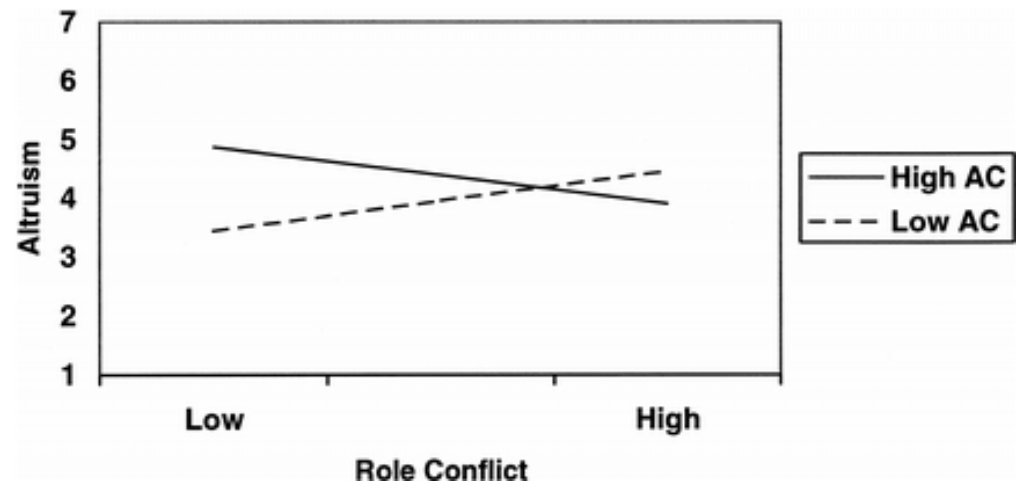


Figure 2. The relation between role conflict and altruism as a function of affective organizational commitment (AC)

\section{Discussion}

The present study investigated relations between work-related stressors and one aspect of employee performance: altruistic behavior directed at fellow employees. The results showed that the three stressors were negatively related to supervisory ratings of altruism, although the magnitude of these relations was modest (range $=-.15$ to -.17 ). Nevertheless, these findings suggest that the presence of stressors in the workplace is associated with a reduction in altruistic behavior among employees. Furthermore, to the extent that extra-role behaviors such as altruism contribute to overall organizational performance (Podsakoff et al., 1997), these findings show one possible mechanism by which workplace stressors may decrease organizational effectiveness.

The results also suggest a possible mechanism by which stressors lead to interpersonal conflict and incivility in the workplace. If an employee's response to stressors is to decrease altruistic behavior toward others, this may lead to decreased altruism on the part of others and may ultimately escalate to conflict and incivility (Andersson \& Pearson, 1999). Unfortunately, this proposition could not be tested in the present study, mainly because we did not measure incivility and because a cross-sectional design was used. This would be interesting to explore in future research, however.

This study also explored the role of affective organizational commitment in the relations between stressors and altruism. The results revealed two moderator effects. As predicted, the presence of organizational constraints was negatively related to altruism among those reporting low levels of organizational commitment. As discussed earlier, this relation could be explained in multiple ways. For example, this relationship can be explained at least partially by the negative psychological reactions typically evoked by stressors such as organizational constraints (Spector \& Jex, 1998). It is also possible that for those low on organizational commitment, withholding of altruistic behaviors represents a safer way to respond to stressors than withholding more highly monitored inrole behaviors. A final possibility is that individuals low on organizational commitment have narrower role boundaries (e.g., Bachrach \& Jex, 2000; Morrison, 1994) and therefore focused on what they perceived as inrole tasks when faced with organizational constraints.

Contrary to predictions, however, the presence of organizational constraints was positively related to altruism among those reporting high levels of affective organizational commitment. Recall that it was hypothesized that there would be no relationship. There are two possible explanations for this finding. First, when performance is constrained, highly committed employees may "pull together" by engaging in altruistic behavior. This, in fact, may be the only way highly committed individuals can help the organization under such conditions. Second, these individuals may also engage in altruistic behavior to directly circumvent organizational constraints. That is, an employee may help a coworker who is in a position to assist when job-related resources are needed. Obviously, neither of these possibilities could be tested in the present study, but both would certainly be interesting to explore in future research.

The interaction effects for role conflict were also at odds with predictions. Specifically, role conflict was negatively related to altruism among those reporting high levels of organizational commitment. This could have been due to the fact that these individuals were focused on mediating the conflicting role demands they were faced with (Tsui, Ashford, St. Clair, \& Xin, 1995). As a result, they may have had less time to engage in altruistic behavior toward other employees. This finding may also reflect the fact that the role demands from the employees' work groups may have been conflicting with those of the organization as a whole. Becker and Billings (1993) pointed out that the focus of employee commitment might be the organization as a whole (labeled globally committed), the immediate work group (labeled locally committed), or a combination of these. Given that altruistic behavior often takes place within work groups, those who were more committed to the organization as a whole (which is what Meyer and Allen's, 1997, measure reflects) may have responded to the 
conflicting role demands by directing their efforts in that direction, and consequently became less altruistic toward members of their immediate work group.

Also contrary to predictions, role conflict was positively related to altruism among those reporting low levels of organizational commitment. There are two possible explanations for this finding. Specifically, individuals with low levels of commitment may have engaged in altruistic behavior as a way of coping with increasing levels of role conflict. Because engaging in helping behavior enhances positive mood (Isen, Shalker, Clark, \& Karp, 1978), this may have been a way of helping these individuals cope with the negative emotions associated with conflicting role demands. It is also possible that those with lower levels of commitment to the organization as a whole may have responded to conflicting role demands by becoming more committed to their immediate work group, and hence more altruistic toward other work group members.

In addition to these moderator effects, it is possible that affective commitment may function as a mediating mechanism between stressors and altruism. That is, stressors may lead to decreased affective commitment, which ultimately leads to decreases in extra-role behaviors such as altruism. This may seem contradictory to the moderator effects, but it is possible for a variable to be both a mediator and a moderator simultaneously (e.g., Jex \& Gudanowski, 1992). For example, the level of commitment an employee has prior to encountering a stressor may moderate reactions to that stressor. However, once a stressor is encountered, one of the consequences may be a reduction in commitment. Unfortunately, the cross-sectional design used in the present study makes it impossible to truly separate moderating and mediating effects. Future longitudinal research, however, would provide much more definitive evidence on this issue.

One limitation of the present investigation was the use of only supervisory ratings to measure altruistic behavior. Although supervisor ratings are commonly used to measure extra-role behavior (e.g., Organ \& Ryan, $\underline{1995)}$, ratings from a single supervisor precluded the calculation of a measure of interrater agreement. Also, in some cases supervisors may not be the best judges of an employee's altruistic behavior.

A second limitation of the present study was the cross-sectional study design. The process by which employees react to stressors clearly takes place over time (McGrath \& Beehr, 1990), and thus using a longitudinal design would have been the best way to capture it. Thus, the present study, like a great deal of occupational stress research, should be considered only a "snap shot" of that process.

A final study limitation was the low response rates for both samples. This raises the possibility that those employees who responded to the survey, and whose supervisors provided altruism ratings, were somehow different from employees who did not provide more complete data. Although some recent work has shown that low response rates do not have a substantive impact on research findings in occupational health research (Schalm \& Kelloway, 2001), it certainly would have been desirable to have had a higher response rate. This is particularly true considering that completion of a survey instrument is itself an altruistic behavior.

The most logical follow-up to the present study would be a replication with a longitudinal design. This would allow greater precision in assessing both the moderating and mediating effects of organizational commitment. Further research is also needed to gain greater insight into the mechanisms responsible for many of the findings. For example, it was proposed that stressors are associated with decreased altruism because of increased negative affect, or perhaps the narrowing of attentional focus. A number of explanations were also given as to why organizational commitment moderated relations between stressor and altruism, and many of these could be reframed into testable research questions.

A final possibility for future research would be to examine relationships between stressors and more than one performance criterion in the same study. Perhaps the most practical way to do such a study would be to examine the relations between the stressors in the present study and both in-role and extra-role performance. 
Such a study would be the most straightforward way to examine whether stressors related differently to different performance criteria (Jex, 1998). Such research would provide insight into the performance-related choices that employees make when faced with various stressors in the work environment.

\section{References}

Abramis, D. J. (1994). Work role ambiguity, job satisfaction, and job performance: Meta-analysis and review. Psychological Reports, 75, 1411-1433.

Allen, N. J., \& Meyer, J. P. (1990). The measurement and antecedents of affective, continuance, and normative commitment to the organization. Journal of Occupational Psychology, 63, 1-18.

Andersson, L. M., \& Pearson, C. M. (1999). Tit for tat? The spiraling effect of incivility in the workplace. Academy of Management Review, 24, 452-471.

Bachrach, D. G., \& Jex, S. M. (2000). Organizational citizenship and mood: An experimental test of perceived job breadth. Journal of Applied Social Psychology, 30, 641-663.

Becker, T. E., \& Billings, R. S. (1993). Profiles of commitment: An empirical test. Journal of Organizational Behavior, 14, 177-190.

Beehr, T. A. (1995). Psychological stress in the workplace. London: Routledge.

Beehr, T. A., \& Bhagat, R. S. (1985). Introduction to human stress and cognition in organizations. In T. A.Beehr \& R. S.Bhagat (Eds.), Human stress and cognition in organizations (pp. 3-19). New York: Wiley.

Beehr, T. A., Jex, S. M., Stacy, B. A., \& Murray, M. A. (2000). Work stressors and coworker support as predictors of individual strain and job performance. Journal of Organizational Behavior, 21, 391-405.

Beehr, T. A., \& Newman, J. E. (1978). Job stress, employee health, and organizational effectiveness: A facet analysis, model, and literature review. Personnel Psychology, 31, 665-699.

Brief, A. P., \& Motowidlo, S. J. (1986). Prosocial organizational behavior. Academy of Management Review, 11, $710-725$.

Cohen, J., \& Cohen, P. (1983). Applied multiple regression/correlation analysis for the behavioral sciences (2nd ed.). Hillsdale, NJ: Erlbaum.

Cohen, S., \& Wills, T. A. (1985). Stress, social support, and the buffering hypothesis. Psychological Bulletin, 98, 310-357.

Damanpour, F. (1991). Organizational innovation: A meta-analysis of effects of determinants of moderators. Academy of Management Journal, 34, 555-590.

Ganster, D. C., \& Schaubroeck, J. (1991). Work stress and employee health. Journal of Management, 17, 235271.

George, J. M., \& Brief, A. P. (1992). Feeling good-doing good: A conceptual analysis of the mood at workorganizational spontaneity relationship. Psychological Bulletin, 112, 310-329.

Graen, G. B. (1976). Role making processes in complex organizations. In M. D.Dunnette (Ed.), Handbook of industrial and organizational psychology (pp. 1201-1245). Chicago: Rand McNally.

Hockey, G. R. J. (1970). Effects of loud noise on information selectivity. Quarterly Journal of Experimental Psychology, 22, 26-28.

Isen, A. M., \& Levin, P. F. (1972). The effect of feeling good on helping: Cookies and kindness. Journal of Personality and Social Psychology, 21, 384-388.

Isen, A. M., Shalker, T. E., Clark, M., \& Karp, L. (1978). Affect, accessibility of material in memory, and behavior: A cognitive loop? Journal of Personality and Social Psychology, 36, 1-12.

Ivancevich, J. M., \& Matteson, M. T. (1980). Stress and work. Glenview, IL: Scott, Foresman.

Jackson, S. E., \& Schuler, R. S. (1985). A meta-analysis and conceptual critique of role ambiguity and role conflict in work settings. Organizational Behavior and Human Decision Processes, 36, 16-78.

Jex, S. M. (1998). Stress and job performance: Theory, research, and implications for managerial practice. Thousand Oaks, CA: Sage.

Jex, S. M., \& Beehr, T. A. (1991). Emerging theoretical and methodological issues in the study of work-related stress. In G. R.Ferris \& K.Rowland (Eds.), Research in personnel and human resources management (Vol. 9, pp. 311-365). Greenwich, CT: JAI Press. 
Jex, S. M., \& Gudanowski, D. (1992). Efficacy beliefs and work stress: An exploratory study. Journal of Organizational Behavior, 13, 509-517.

Jex, S. M., \& Spector, P. E. (2002, April). Interpersonal conflict at work: Organizational context and employee disposition, performance, and health. In A.Grandey (Chair), Coping with incivility, hostility, and abuse in the workplace. Symposium conducted at the Society for Industrial and Organizational Psychology Convention, Toronto, Ontario, Canada.

Kahn, R. L., \& Byosiere, P. (1992). Stress in organizations. In M. D.Dunnette \& L. M.Hough (Eds.), Handbook of industrial and organizational psychology (2nd ed., Vol. 3, pp. 571-650). Palo Alto, CA: Consulting Psychologists Press.

Matthews, K. E., \& Canon, L. K. (1975). Environmental noise level as a determinant of helping behavior. Journal of Personality and Social Psychology, 32, 571-577.

McGrath, J. E., \& Beehr, T. A. (1990). Time and the stress process: Some temporal issues in the conceptualization and measurement of stress. Stress Medicine, 6, 93-104.

Meyer, J. P., \& Allen, N. J. (1997). Commitment in the workplace: Theory, research, and application. Thousand Oaks, CA: Sage.

Morrison, E. W. (1994). Role definitions and organizational citizenship behavior: The importance of the employee's perspective. Academy of Management Journal, 37, 1543-1567.

Motowidlo, S. J., Packard, J. S., \& Manning, M. R. (1986). Occupational stress: Its causes and consequences for job performance. Journal of Applied Psychology, 71, 618-629.

Murphy, K. R. (1994). Toward a broader conceptualization of jobs and job performance: Impact of changes in the military environment on the structure, assessment, and prediction of job performance. In M. G.Rumsey, C. B.Walker, \& J. H.Harris (Eds.), Personnel selection and classification (pp. 85-102). Hillsdale, NJ: Erlbaum.

Murphy, K. R., \& Cleveland, J. N. (1990). Performance appraisal: An organizational perspective. Boston: Allyn \& Bacon.

Organ, D. W. (1988). Organizational citizenship behavior: The good soldier syndrome. Lexington, MA: Lexington Books.

Organ, D. W. (1994). Organizational citizenship and the good soldier. In M. G.Rumsey, C. B.Walker, \& J. H. Harris (Eds.), Personnel selection and classification (pp. 53-67). Hillsdale, NJ: Erlbaum.

Organ, D. W., \& Ryan, K. (1995). A meta-analytic review of attitudinal and dispositional predictors of organizational citizenship behavior. Personnel Psychology, 48, 775-802.

Peters, L. H., \& O'Connor, E. J. (1980). Situational constraints and employee affective reactions: The influences of a frequently overlooked construct. Academy of Management Review, 5, 391-397.

Podsakoff, P. M., Ahearne, M., \& MacKenzie, S. B. (1997). Organizational citizenship behavior and the quantity and quality of work group performance. Journal of Applied Psychology, 82, 262-270.

Podsakoff, P. M., MacKenzie, S. B., Paine, J. B., \& Bachrach, D. G. (2000). Organizational citizenship behaviors: A critical review of the theoretical and empirical literature and suggestions for future research. Journal of Management, 26, 513-563.

Rizzo, J. R., House, R. J., \& Lirtzman, S. I. (1970). Role conflict and ambiguity in complex organizations. Administrative Science Quarterly, 15, 150-163.

Schalm, R. L., \& Kelloway, E. K. (2001). The relationship between response rate and effect size in occupational health research. Journal of Occupational Health Psychology, 6, 160-163.

Sherrod, D. R., \& Downs, R. (1974). Environmental determinants of altruism: The effects of stimulus overload and perceived control on helping. Journal of Experimental Social Psychology, 10, 468-479.

Spector, P. E., \& Jex, S. M. (1998). Development of four self-report measures of job stressors and strain: Interpersonal Conflict at Work Scale, Organizational Constraints Scale, Quantitative Workload Inventory, and Physical Symptoms Inventory. Journal of Occupational Health Psychology, 3, 356-367.

Tsui, A. S., Ashford, S. J., St. Clair, L., \& Xin, K. R. (1995). Dealing with discrepant expectations: Response strategies and managerial effectiveness. Academy of Management Journal, 38, 1515-1543. 